https://doi.org/10.18800/iusetveritas.201703.005 (c) (i)

\title{
Apuntes en torno a las prácticas antisindicales: ¿Es realmente posible probarlas? ${ }^{*}{ }^{*}$
}

Notes about anti union practices: it is really possible to test them?

\author{
Lidia Vilchez Garcés ${ }^{(* *)}$ \\ Asociada Principal de Phillipi, Prietocarrizosa, Ferrero DU \& Uría
}

\begin{abstract}
Resumen: En el presente artículo, se analiza una de las instituciones del derecho laboral más importantes, como lo es la libertad sindical(1) y, en contrapartida, la más clara manifestación de su vulneración: la conducta antisindical. El tema reviste complejidad, en la medida que este tipo de conductas proscritas se puede materializar de distintas y sutiles formas, siendo de especial interés, abordar la injerencia del empleador en la administración del Sindicato, así como las dificultades que entraña su probanza.
\end{abstract}

Palabras claves: Prácticas Antisindicales - Libertad Sindical - Empleador - Entidades Públicas

\begin{abstract}
In this article, one of the most important labor law institutions is reviewed, as it is freedom of association and, in return, the clearest statement of its violation: anti-union behavior. The issue highlights complexity, in so far as this type of proscribed behaviors can be realize in different and subtle ways, being of special interest to address the interference of the employer in the administration of the labor union, as well as the difficulties involved in its evidence.
\end{abstract}

Keywords: Anti Union Practices - Syndical freedom - Employer - Public Entities

Sumario: 1. Introducción_2. Nociones básicas: libertad sindical y prácticas antisindicales_2.1 Definiendo al complejo derecho a la libertad sindical: breves apuntes_2.2 Las prácticas antisindicales como antagonistas al derecho a la libertad sindical_2.3 Medidas normativas de proscripción de las

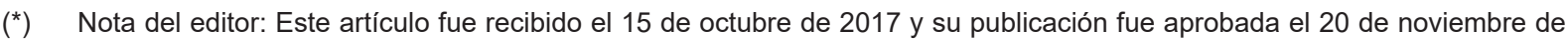
2017.

${ }^{(* *}$ Magíster en Derecho del Trabajo y la Seguridad Social por la Pontificia Universidad Católica del Perú. Estudios de Post Grado en Derecho del Trabajo en la Universidad Complutense de Madrid, Universidad de Salamanca y Universidad de Castilla La Mancha.

(1) Freedom of association, Unfair labor practice, employer's interference, proof. 
Apuntes en torno a las prácticas antisindicales: ¿Es realmente posible probarlas? Notes about anti union practices: it is really possible to test them?

prácticas antisindicales y situación actual en América Latina_2.3.1 Primera aproximación a las prácticas antisindicales: Wagner Act de 1935_2.3.2 Convenio OIT 98_2.3.3 Regulación latinoamericana de las prácticas antisindicales_3. ¿Qué se entiende por prácticas antisindicales?_3.1 Clasificación de prácticas antisindicales_3.1.1 Prácticas dirigidas contra sindicalistas a título individual_3.1.2 Acciones u omisiones de las autoridades públicas en desmedro de los sindicatos_3.1.3 Prácticas del empleador contra el sindicato como entidad colectiva_4. La prueba en materia de prácticas antisindicales y actos de injerencia_5. Conclusiones_ 6. Referencias bibliográficas.

\section{Introducción}

El derecho laboral tiene un lugar preponderante como objeto de estudio jurídico gracias a su reconocimiento como uno de los pilares fundamentales para el crecimiento económico global. Adicionalmente, se ha reconocido el rol integral del Estado, de las organizaciones de trabajadores y de empleadores en la reglamentación de las relaciones de trabajo y en la creación de políticas que trascienden a lo meramente privado y que pueden llegan incluso a fijar el norte económico de un país. Así, el diálogo social y la concertación se sitúan en una posición preponderante en la agenda social y económica actual.

En este contexto, se ha producido en el Perú un fenómeno interesante de crecimiento de la actividad sindical, crecimiento que supone el incremento -aún incipiente - en los niveles de constitución de organizaciones sindicales y en la afiliación de trabajadores a los sindicatos ya existentes, ya sean estos de primer nivel o de niveles superiores. Este crecimiento, si bien debería suponer el reforzamiento de las estructuras negociales reduciendo la tradicional desigualdad de poderes entre empleador y trabajador, da lugar al fortalecimiento de una percepción negativa del sector empresarial, respecto de la actividad sindical al interior de sus organizaciones.

Esta percepción de los empleadores respecto de toda forma de actividad asociativa de los trabajadores fortalece a su vez, junto con la actividad sindical, la implementación de prácticas antisindicales y, dentro de ellas, los actos de injerencia, tema que se alude en el presente Trabajo, poniendo énfasis en sus distintas clases de manifestaciones, así como en las dificultades que plantea la probanza en esta clase de prácticas desleales.

\section{Nociones básicas: libertad sindical y prácticas antisindicales}

Conforme a lo anticipado, corresponde analizar con mayor profundidad, lo siguiente: (i) qué se entiende por práctica antisindical (o prácticas desleales); (ii) cómo se clasifican tales conductas; (iii) cómo demostrar su configuración, y; (iv) cuál es su impacto en la lógica de protección de derechos fundamentales de la persona, en una realidad como la peruana, en la cual la actividad sindical está recobrando paulatinamente fuerza en las relaciones laborales, principalmente a nivel de empresa.

En este entendido, corresponde detenerse por un momento en cuál es el derecho fundamental vulnerado cuando se producen prácticas antisindicales. Pues bien, lo que se busca cautelar al proscribir este tipo de prácticas o conductas (en su mayoría patronales, si bien no exclusivamente) es la libertad sindical de los trabajadores, concepto al cual se aludirá sucintamente.

2.1 Definiendo al complejo derecho a la libertad sindical: breves apuntes

A lo largo de los años, la doctrina ha ido perfilando un concepto de libertad sindical que ha evolucionado para llegar a ser hoy, en materia de derecho laboral, el derecho fundamental más reconocido y cuya tutela se persigue con más determinación. Así, la Organización Internacional del Trabajo (en adelante, "OIT"), atendiendo a la relevancia social del derecho a la libertad sindical creó en el año 1951, el Comité de Libertad Sindical del Consejo de Administración de la OIT (en adelante, "CLS"), organismo que se reúne tres veces al año con la finalidad exclusiva de analizar denuncias "generalmente planteadas por organizaciones sindicales contra gobiernos, en las que se alega la violación de los principios de libertad sindical" (Ermida 1988, 20). 
Lidia Vilchez Garcés

En este sentido, si bien inicialmente ese entendía por libertad sindical únicamente, el derecho de constituir organizaciones (ya sea por parte de trabajadores como empleadores), hoy se le reconoce una naturaleza más bien compleja y de suma trascendencia (Levaggi 2006, 136) (2), compuesta por una serie de derechos, tanto positivos como negativos, e individuales (que se refieren al individuo en el marco de la organización sindical) y colectivos (referidos a la organización en su conjunto entendida como un todo).

Así, el concepto de libertad sindical en nuestros días goza de reconocimiento en distintos niveles, debiendo - para brindar una definición acuciosa - analizar transversalmente todos los derechos y libertades reconocidos tanto en el Convenio OIT 87 (Convenio sobre la libertad sindical y la protección del derecho de sindicación) como en el Convenio OIT 98 (Convenio sobre el derecho de sindicación y negociación colectiva), los cuales dotan de contenido el concepto de libertad sindical.

Entre los principales derechos reconocidos, encontramos el derecho de los trabajadores, por un lado, y de los empleadores por otro, de asociarse libremente con la finalidad de organizar, promover y defender sus intereses profesionales, sin necesidad de autorización previa. De acuerdo con lo señalado por la OIT, se trata de un "derecho humano básico íntimamente ligado a la libertad de expresión y es la base de la gobernabilidad y la representación democrática" (OIT 2002, 9). Así lo ha establecido el artículo 2 del Convenio OIT 87, el cual señala que "los trabajadores y los empleadores, sin ninguna distinción y sin autorización previa, tienen el derecho de constituir las organizaciones que estimen convenientes, así como el de afiliarse a estas organizaciones, con la sola condición de observar los estatutos de las mismas."

En adición a ello, el Convenio OIT 87 consagra en su articulado otros derechos, tales como el derecho de organizar libremente las actividades del sindicato, el derecho de obtener personería jurídica, el derecho a constituir federaciones y confederaciones, y el derecho de afiliarse a organizaciones sindicales internacionales. Por su parte, el Convenio OIT 98 reconoce el derecho de protección contra los actos de discriminación orientada a perjudicar a los trabajadores organizados en su empleo, así como contra cualquier acto de injerencia en la constitución, funcionamiento y organización. Así, el referido Convenio, ha definido los actos de injerencia, conforme a lo que a continuación se transcribe:

"Artículo 2.2.- Se consideran actos de injerencia, en el sentido del presente artículo, principalmente las medidas que tiendan a fomentar la constitución de organizaciones de trabajadores dominadas por un empleador o una organización de empleadores, o a sostener económicamente, o en otra forma, organizaciones de trabajadores, con el objeto de colocar estas organizaciones bajo el control de un empleador u organización de empleadores."

En adición a estos derechos, se discute sobre el derecho a la libertad sindical negativa (entendido este como el derecho a no afiliarse a un sindicato o a desafiliarse a él), derecho no reconocido expresamente en los convenios de la OIT, pero que ha sido reconocido por la doctrina. Respecto de este derecho, Ermida señala que "la admisión sin reservas de tal libertad sindical negativa implica la interdicción total o parcial, de las denominadas "cláusulas sindicales" o "cláusulas de seguridad", concepto ampliamente discutido, existiendo algunos importantes autores (tales como Octavio de Bueno Magano) que no consideran a la libertad sindical negativa como un derecho individual, sino como un derecho colectivo con consecuencias fortificadoras de su estructura (Ermida 1988, 32).

(2) De este modo, se postula que "la promoción de los principios de libertad sindical y de asociación y negociación colectiva es fundamental para que se pueda progresar en el cumplimiento de los derechos fundamentales y, por tanto, en el logro de los objetivos de generación de trabajo decente y consolidación democrática en la región. Las relaciones laborales son elementos básicos del progreso económico y social de los países" Véase, Virgilio Levaggi, Democracia y trabajo decente en América Latina (Lima: Oficina Internacional del Trabajo, 2006). 
Apuntes en torno a las prácticas antisindicales: ¿Es realmente posible probarlas? Notes about anti union practices: it is really possible to test them?

\subsection{Las prácticas antisindicales como antagonistas al derecho a la libertad sindical \\ Atendiendo a cuáles son los principales derechos reconocidos en materia de libertad sindical, resulta necesario ahora analizar qué se entiende por prácticas o conductas antisindicales, en contraposición con el derecho fundamental referido anteriormente.}

Este concepto, si bien tiene reconocimiento y proscripción normativa desde hace muchísimos años, siendo su partida de nacimiento, el Wagner Act (Estados Unidos, 1935), y recogido en el artículo 2 del convenio OIT 98 de 1949, en Perú viene cobrando importancia como tema de discusión ante el resurgimiento progresivo, después de muchos años de letargo, de la actividad sindical.

La referida norma estadounidense, denominada formalmente Ley Nacional de Relaciones de Trabajo (Nacional Labor Relations Act), fue la primera norma que reguló este tipo de conductas contrarias al reconocimiento a la libertad sindical. Llama la atención que haya sido precisamente Estados Unidos, país eminentemente liberal, quien sentara las bases del objeto de estudio. Así, cabe recordar lo señalado por Ermida, quien sostiene lo que seguidamente se transcribe:

"[E]n un sistema jurídico laboral en principio abstencionista, autónomo y liberal como, al menos en teoría, es el estadounidense, la introducción de la proscripción de las prácticas desleales (...) implica, por una parte, introducir determinadas protecciones al ejercicio de los derechos sindicales en un esquema general de fair play y, por otra, procurar que las limitaciones que por esa vía se imponían al libre juego de las partes estuvieran fundamentadas en la necesidad de introducir o asegurar la ética de las relaciones laborales" (Ermida 1987, 11).

Así, el tema de las prácticas desleales cuenta con una amplia regulación en Estados Unidos, regulación que se encuentra recogida también en numerosos ordenamientos latinoamericanos, que, en mayor o menor detalle han recogido las provisiones normativas contenidas en el Wagner Act y en el Convenio OIT 98, a las cuales se alude más adelante.
2.3 Medidas normativas de proscripción de las prácticas antisindicales y situación actual en América Latina

Toda vez que la comisión de prácticas antisindicales supone una gravísima trasgresión a la libertad sindical, derecho fundamental abordado con anterioridad, aquellas merecido si bien con distinta fuerza, rechazo de manera unánime a través de distintas legislaciones y prácticas nacionales.

2.3.1 Primera aproximación a las prácticas antisindicales: Wagner Act de 1935

Así, conforme se indica anteriormente, la norma primigenia en materia de proscripción de prácticas antisindicales es el Wagner Act de 1935. Dicha norma, contiene, al referirse a los "Unfair Labor Practices", en su Sección 8(a)1, una primera aproximación genérica a las referidas prácticas, prohibiendo al empleador interferir, restringir o coaccionar a los trabajadores que hagan uso de los derechos reconocidos en el Wagner Act (Covington y Decker 2002, 266).

Acto seguido prohíbe conductas desleales específicas, entre las cuales se señala que un empleador no puede:

"dominar, sostener o interferir con la formación o administración de una organización de trabajo, ni discriminar en la contratación, conservación del empleo ni en ninguna condición de empleo en forma alguna que desincentive la participación en una organización de trabajadores, tomar represalias contra un trabajador que denuncie prácticas desleales, o rehúse negociar colectivamente con los representantes de los trabajadores"(3) (Covington y Decker 2002, 267).

(3) 'This may occur when an employer refuses to negotiate with the employees' certified or recognized representatives, refuses to arbitrate under a collective agreement, or engages in conduct to frustrate reaching an agreement" Véase Covington, R. y Decker K. 2002. Employment Law. U.S.A: West Group. 
Tal y como se indica con anterioridad, llama la atención el detalle del desarrollo normativo aportado por la legislación estadounidense respecto a las prácticas sindicales. Es interesante apreciar cómo una legislación de más de ochenta años de antigüedad se encuentra completamente vigente $y$, de ser aplicada en Perú, sería de sumo útil para enfrentar la problemática generada por la comisión de dicha clase de prácticas en perjuicio de la libertad sindical, atendiendo a la renuencia que tienen nuestros aplicadores de justicia, de fundar sus decisiones en normas supranacionales, como lo es el Convenio OIT 98.

\subsubsection{Convenio OIT 98}

El Convenio sobre el derecho de sindicación y negociación colectiva, norma internacional (adoptada en Ginebra en 1949 y ratificada por el Perú mediante Resolución Legislativa No. 14712 de fecha 18 de noviembre de 1961), desarrolla con precisión el tema de las prácticas desleales. Así, en su artículo 1, el Convenio hace referencia a la protección contra actos de discriminación por motivos sindicales, mientras que en el artículo 2 , alude a los actos de injerencia de las organizaciones de trabajadores respecto de las de empleadores y viceversa (Ermida 1987, 16-17) ${ }^{(4)}$.

En líneas generales, estas normas, proscriben las siguientes conductas:

- Sujetar el empleo de un trabajador a condición de no afiliarse a un sindicato o a que se desafilie.

- Despedir o perjudicar a un trabajador a causa de su afiliación o participación en actividad sindical.
- Fomentar la constitución de organizaciones de trabajadores dominadas por un empleador.

- Sostener económicamente o de otra firma a un sindicato con la finalidad de controlarlo.

2.3.3 Regulación latinoamericana de las prácticas antisindicales

En adición a lo anteriormente referido, cabe anotar que, en distintos países de América Latina, el fenómeno objeto de estudio está regulado de manera unánime, si bien de diversa manera y con distinta intensidad, atendiendo a las distintas alternativas legislativas de los gobiernos. Dentro de estas encontramos algunas legislaciones sumamente específicas, que describen en detalle cuáles son las prácticas antisindicales, mientras que otras se remiten directa o indirectamente a los alcances del Convenio OIT 98, ratificado de manera general por los distintos Estados de esta parte del mundo.

Respecto del primer grupo, encontramos la regulación de Costa Rica, con una regulación amplia(5), y las legislaciones de Perú, Argentina, Colombia y Uruguay(6), las cuales contienen también protección amplia, la cual engloba a la negociación colectiva y otras actividades propias de la vida sindical.

(4) Sobre esta distinción entre discriminación y actos de injerencia, Ermida realiza una distinción importante, para luego concluir que ambas conductas pueden perfectamente englobarse en el concepto de práctica antisindical. Así, sostiene que: "la diferencia más precisa entre los actos de discriminación antisindical y los actos de injerencia (...) parece radicar en que los primeros se dirigen más directamente a uno o varios trabajadores - por más que - tal conducta agreda tanto valores o intereses individuales de ese o esos trabajadores, como colectivos (...), mientras que los segundos se dirigen más directamente contra la organización profesional. La expresión (de prácticas, actos o conductas antisindicales) englobando en un solo concepto los actos de discriminación antisindical, los actos de injerencia y las prácticas desleales". Véase Oscar Ermida Uriarte, La Protección contra los actos antisindicales (Montevideo: Fundación de Cultura Universitaria, 1987).

(5) El Código de Trabajo de Costa Rica, señala lo siguiente: "Artículo 363.- Prohíbanse las acciones u omisiones que tiendan a evitar, limitar, constreñir o impedir el libre ejercicio de los derechos colectivos de los trabajadores, sus sindicatos o las coaliciones de trabajadores".

Cualquier acto que de ellas se origine es absolutamente nulo e ineficaz y se sancionará, en la forma y en las condiciones señaladas en el Código de Trabajo, sus leyes supletorias o conexas para la infracción de disposiciones prohibitivas"

(6) Argentina, por ejemplo, contempla en el artículo 53 de la Ley 23551, once supuestos de prácticas contrarias a la libertad sindical. Por su parte, Panamá recoge el concepto de listas negras, como una práctica prohibida, mientras que Colombia (artículo 354 del Código Sustantivo de Trabajo y artículo 292 del Código Penal) y Uruguay (artículo 1 de la Ley 17940) cuentan con una lista de conductas prohibidas. 
Apuntes en torno a las prácticas antisindicales: ¿Es realmente posible probarlas? Notes about anti union practices: it is really possible to test them?

En Perú, el artículo 4 del Decreto Supremo 010-2003-TR dispone que "El Estado, los empleadores y los representantes de uno y otros, deberán abstenerse de toda clase de actos que tiendan a coactar, restringir o menoscabar, en cualquier forma, el derecho de sindicalización de los trabajadores, o de intervenir en modo alguno en la creación, administración o sostenimiento de las organizaciones sindicales que estos constituyan." Por su parte, el Reglamento de la Ley General de Inspección del Trabajo (Decreto Supremo 019-2006-TR y sus normas modificatorias) incorpora un listado enunciativo de conductas consideradas infracciones en materia socio laboral por, justamente, su carácter lesivo de la libertad sindical.

Pese a que en términos formales, como señalamos, sí existe en mayor o menor medida regulación sobre la materia, es de particular interés el hecho de que la mayor parte de denuncias planteadas ante el CLS y de observaciones de la Comisión de Expertos en la Aplicación de Convenios y Recomendaciones de la OIT provengan de América Latina, lo cual puede ser enfocado desde dos perspectivas: la primera, desde un plano negativo, que evidenciaría una violación sistemática de derechos, superior a la que se podría producir en otras partes del mundo y; desde otra perspectiva, más alentadora, podría suponer que en efecto hay una mayor noción de la libertad sindical como un derecho fundamental, lo cual determina una mayor cantidad de cuestionamientos ante los incumplimientos producidos por empleadores o por los propios gobiernos.

Esta segunda posición es suscrita por María Luz Vega, quien señala lo que a continuación se reproduce:

"En efecto, quizás sea ese mencionado aumento del número de denuncias nacionales e internacionales sobre los incumplimientos en esta materia, tanto por parte de organizaciones de trabajadores, como de empleadores, un elemento revelador de la relevancia social y política del tema. Que las Américas representen el mayor número (regional) de quejas en materia de libertad sindical, no prueba a la existencia de mayores vulneraciones o incumplimientos en el mundo, sino quizás un mayor conocimiento de la importancia a todos los niveles del derecho, de su valor y sus garantías, tanto en el ámbito nacional como internacional" (Vega 2004, 8).

En este mismo sentido, Levaggi reconoce que "América Latina tiene más de la mitad de las quejas presentadas a la OIT a nivel mundial y una de las tasas más altas de sindicalistas asesinados o despedidos arbitrariamente. Si bien esta proporción puede ser evidencia de que en América Latina se conocen mejor los órganos de control de la OIT, recurriendo a ellos con mayor frecuencia" (Levaggi 2006, 136).

Una vez concluido el estudio general de la noción, regulación y alcances del concepto de libertad sindical su protección en la región corresponde revisar la noción de prácticas antisindicales, sus características y algunos ejemplos, de acuerdo con pronunciamientos de distintos órganos protectores de la institución jurídica de la libertad sindical.

\section{3. ¿Qué se entiende por prácticas antisindicales?}

Se definen las prácticas antisindicales como aquellas conductas, principal pero no exclusivamente del empleador $u$ organizaciones de empleadores, orientadas a menoscabar el derecho al libre ejercicio de la libertad sindical por parte de los trabajadores, buscando evitar que los afiliados a las organizaciones sindicales puedan ejercer los derechos fundamentales reconocidos en los convenios internacionales referidos anteriormente.

Mediante estas prácticas se persigue - en el momento genético de la organización colectiva, limitar o impedir de cualquier forma, el derecho de los trabajadores de agruparse colectivamente para la defensa de sus intereses. Asimismo, una vez creada la organización, se busca restringir su actividad, intentando controlar a las organizaciones, a sus representantes, afectando el derecho a organizar sus actividades de manera autónoma, con la evidente finalidad de eliminar los sindicatos, reduciendo así las posibilidades de verse obligados a llevar a cabo procedimientos de negociación colectiva 


\section{Lidia Vilchez Garcés}

o encontrarse sometidos a medidas de fuerza para el logro de reivindicaciones salariales y sociales.

Si bien las prácticas antisindicales tradicionalmente han sido llevadas a cabo por los empleadores, no se limitan a los referidos sujetos activos. Por el contrario, esta clase de práctica también puede ser llevada a cabo por otros agentes, tales como las autoridades gubernamentales. En efecto, para aquellas, eventualmente la actividad sindical podría ser entendida como un obstáculo en la realización de determinados objetivos nacionales.

Un claro ejemplo de lo anteriormente expuesto se presentó a inicios de la década de los noventa en el Perú, época en la cual la actividad sindical se vio reducida dramáticamente precisamente a raíz de políticas legislativas orientadas a flexibilizar la economía, y que consideraban al trabajador organizado, como un obstáculo para el crecimiento del país, persiguiendo en consecuencia la desaparición de los sindicatos como organizaciones representativas de los intereses de los trabajadores. Ello llevó a la publicación del Decreto Ley 25593 (Ley que regula las relaciones laborales de los trabajadores sujetos al régimen de la actividad privada), norma que en su redacción original contenía una serie de restricciones y limitaciones a la actividad sindical ${ }^{(7)}$.

Asimismo, y si bien este tema ha sido menos desarrollado, también es posible hablar de prácticas antisindicales realizadas por la propia organización de trabajadores. Esto, por ejemplo, se configura con la implementación de cláusulas sindicales, comunes en los sistemas anglosajones. Algunos ejemplos de estas cláusulas son la cláusula closed shop o taller cerrado, en cuyo marco se prohíbe a un empleador contratar a un trabajador que no se encuentre afiliado a determinado sindicato; la cláusula union shop o taller sindical, por la cual el empleador puede contratar trabajadores no afiliados, pero con el empleo condicionado a que estos se afilien a determinado sindicato; preferential shop o cláusulas preferenciales, que conceden beneficios especiales al interior de la empresa a los trabajadores afiliados al sindicato, entre otras (Ermida 1988, 34).

Otro supuesto de prácticas antisindicales se da cuando la comisión negociadora sindical de un pliego de reclamos o la junta directiva de una organización sindical toma de manera unilateral la decisión de acudir a una huelga, pese a no haber sido aquella una decisión tomada de manera democrática en asamblea, alterando así la facultad de organización y de toma de decisiones de los trabajadores como ente colectivo. Otra práctica que es calificada de antisindical por parte del CLS es la utilización del cargo de un dirigente sindical para ejercer presión sobre los demás empleados. Así, en un caso examinado, el referido Comité respaldó la conclusión de un tribunal nacional, el cual concluyó que:

"una de las razones del despido de un dirigente sindical fue la de que ejercía actividades sindicales (...) ocupando el personal de empleador para fines sindicales y utilizando su protección en la empresa para ejercer presiones indebidas sobre otro empleado. (...) El Comité opinó que cuando las actividades sindicales se cumplen de esa forma, la persona no puede invocar la protección del Convenio núm. 98 o, en caso de despido, alegar que se han violado legítimos derechos sindicales. (Recopilación de 1985, párrafo 556.)" (OIT 1995, 157).

Un escenario interesante adicional de prácticas desleales (siguiendo la acepción estadounidense de unfair labor practices), se genera ante las conductas cometidas por las organizaciones de trabajadores en agravio del empleador, utilizando la violencia, la represión o la negativa a negociar dentro de los parámetros de la buena fe.

3.1 Clasificación de prácticas antisindicales Siguiendo con los criterios esgrimidos en los párrafos que anteceden, se clasifican las prácticas o conductas antisindicales, tomando

(7) Restricciones que se fueron eliminando paulatinamente a raíz de la intervención de la OIT y los numerosos pronunciamientos del Comité de Libertad Sindical y la Comisión de Expertos en la Aplicación de los Convenios y Recomendaciones de la OIT. 


\section{Apuntes en torno a las prácticas antisindicales: ¿Es realmente posible probarlas? Notes about anti union practices: it is really possible to test them?}

como referencia el esquema propuesto por Arturo Bronstein al respecto. De este modo, el referido laboralista clasifica dichas prácticas en tres grandes grupos, enumerados a continuación:

- Prácticas del empleador en contra de sindicalistas a título individual.

- Acciones u omisiones de las autoridades públicas en desmedro de los sindicatos.

- Prácticas del empleador contra el sindicato como entidad colectiva.

3.1.1 Prácticas dirigidas contra sindicalistas a título individual: Estas conductas están orientadas principalmente a impedir la afiliación a un sindicato, la constitución misma, la elección libre - por cada uno de los trabajadores - de sus representantes, o la toma de represalias por el desarrollo de actividad sindical. Al respecto, Bronstein señala que:

"algunas de ellas pueden ser de tipo preventivo, cuando persiguen (...) impedir la constitución de un sindicato, o de impedir que los trabajadores adhieran a un sindicato ya constituido, o impedir que el sindicato designe a sus autoridades. Otras son de tipo represivo, cuando consisten en la adopción de represalias contra trabajadores, con motivo del ejercicio de sus derechos sindicales" (Bronstein, 1995, 89).

Adicionalmente, y sin perjuicio de la calificación propuesta, cabe señalar que también, si bien de difícil probanza, se producen prácticas antisindicales en la etapa previa a la contratación del trabajador, a través de la utilización por parte de los empleadores, de las llamadas listas negras ${ }^{(8)}$. Sobre el particular, se ha señalado lo siguiente:

"Los trabajadores tienen muchas dificultades de orden práctico para probar la naturaleza real de su despido o de la negativa de un empleo, especialmente cuando el problema se examina dentro del contexto de las listas negras, práctica cuya fuerza radica precisamente en su carácter secreto. Si es cierto que para los empleadores es importante obtener información sobre sus eventuales asalariados, no es menos cierto que a los trabajadores que en otros tiempos hayan estado afiliados a un sindicato o hayan desarrollado actividades sindicales, se les debería comunicar la información que sobre ellos se tenga, ofreciéndoles la oportunidad de impugnarla, especialmente si es errónea y se ha obtenido de una fuente que no sea digna de crédito. Además, en estas condiciones, los trabajadores interesados serían más propensos a instituir un procedimiento legal, ya que se hallarían en una mejor posición para demostrar la naturaleza real de (...) la negativa de empleo" (OIT 2006, 168).

En este escenario, de lo que se trata es de permitir al trabajador cuyo nombre aparezca en una lista negra, conocer el motivo real de su no contratación, y en dicho marco, impugnar la decisión patronal, contando con elementos probatorios, situación que no se podría materializar en un escenario de discriminación por antecedente sindical, pues el potencial empleador jamás reconocerá que la no contratación obedeció a un motivo prohibido, sino a cualesquiera otros motivos, sin estar el trabajador no contratado en posibilidad real de demostrar que la no contratación obedece a causas discriminatorias.

En otro extremo, ya durante la contratación, conforme se señala, se pueden producir conductas patronales destinadas a impedir que un trabajador se afilie a un sindicato, a través de actos de acoso o intimidación, o condicionamiento de la renovación de los contratos sujetos a modalidad a la no afiliación a un sindicato. Respecto del primer supuesto, el CLS ha señalado que "los actos de acoso e intimidación perpetrados contra los trabajadores con motivo de su afiliación sindical o de sus actividades sindicales

(8) El CLS ha señalado al respecto que "la práctica consistente en establecer listas negras de dirigentes sindicales y sindicalistas constituye una grave amenaza para el libre ejercicio de los derechos sindicales, y en general, los gobiernos deberían tomar medidas enérgicas para combatir estas prácticas". Véase Informe CLS Caso No. 2274, párrafo 1125. 
legítimas, aunque no impliquen necesariamente perjuicios en su empleo, pueden desalentarlos de afiliarse a las organizaciones de su elección, lo cual constituye una violación a su derecho de sindicación" (OIT 2006, 168).

Por su parte, la no renovación del contrato sujeto a modalidad o a plazo fijo con motivo de la afiliación a un sindicato supone una violación tanto al derecho de libertad sindical del trabajador como a su derecho en la estabilidad en el empleo. Ello se configura usualmente en realidades de inestabilidad laboral y fragilidad sindical como la peruana, y se manifiesta a través del condicionamiento de la renovación de estos contratos a la no afiliación a una organización sindical.

Así, el trabajador que se considere afectado tendrá que demostrar una doble violación: por un lado, la desnaturalización de la contratación temporal (demostrando la inexistencia de una causa objetiva que justifique la contratación), y por tanto se trató de un despido incausado y que corresponde la reposición; y, por otro lado, que dicho despido obedeció en realidad a su afiliación a una organización sindical. La actividad probatoria respecto de ambos supuestos, como es evidente, puede resultar compleja y se debe desenvolver en el marco de un proceso judicial, colocando al trabajador afectado en una posición de indefensión tal, que lleva a pensar en la pertinencia de disponer la inversión de la carga de la prueba a su favor.

Por otro lado, otra práctica antisindical común que se sitúa dentro de esta primera categoría es el despido de trabajadores con motivo de su pertenencia a organizaciones sindicales, principalmente de dirigentes de las referidas agrupaciones.

Esta situación ha sido materia de numerosos pronunciamientos del CLS, en tanto que estos despidos, si bien individuales, tienen un doble impacto, afectando la libertad sindical no sólo del trabajador a título individual sino también la de la organización en su conjunto, al señalar que "la estabilidad laboral, al alejar el peligro de la pérdida del empleo a causa del ejercicio de los derechos colectivos, fortalece la capacidad de organización y el ejercicio de la autonomía colectiva" (Blancas 2006, 87), debilitando su fuerza respecto de la contraparte empleadora.

Así, coincidimos con lo resuelto - por primera vez, por el Tribunal Constitucional en el célebre caso Baylón Flores, lo siguiente:

"Es por ello que, a criterio del Tribunal Constitucional, la dimensión plural o colectiva de la libertad sindical garantiza no sólo la protección colectiva de los trabajadores sindicalizados, sino que también recoge una protección especial para los dirigentes sindicales (...) Consecuentemente, todo acto lesivo, no justificado e irrazonable que afecte a los trabajadores sindicalizados y a sus dirigentes y que haga impracticable el funcionamiento del sindicato, deberá ser reparado"(9).

Asimismo, el referido Colegiado resolvió lo que a continuación se transcribe:

“(...) Todo ello demuestra que, en rigor, nos encontramos frente a un despido masivo y simultáneo dirigido contra los dirigentes sindicales y algunos afiliados del recurrente. Dicho acto lesivo vulnera el derecho de sindicación y de libertad sindical en su dimensión plural, que protege al Sindicato, a sus dirigentes y a sus afiliados cuando colectivamente ejercen el mencionado derecho"(10).

3.1.2 Acciones u omisiones de las autoridades públicas en desmedro de los sindicatos Si bien es común que las prácticas antisindicales sean implementadas por parte

(9) Sentencia recaída en el Expediente 0206-2005-PA/TC con fecha 28 de noviembre de 2005 en proceso de amparo seguido por César Antonio Baylón Flores.

(10) Sentencia recaída en el Expediente 3311-2005-PA/TC con fecha 5 de enero de 2006 en proceso de amparo seguido por el Sindicato de Trabajadores Mineros de Atacocha. 


\section{Apuntes en torno a las prácticas antisindicales: ¿Es realmente posible probarlas? Notes about anti union practices: it is really possible to test them?}

de los empleadores, es incuestionable que los gobiernos también, en tanto agentes comprendidos dentro del sistema colectivo, pueden ser sujetos activos en materia de prácticas antisindicales.

Con relación a este tercer grupo de prácticas, se encuentran las prácticas administrativas de disolución de sindicatos y negativa injustificada a la concesión del registro ante la Autoridad de Trabajo.

Adicionalmente, estas conductas pueden configurarse con un alcance mucho más amplio ( $\mathrm{y}$, por tanto, peligroso), a través de políticas legislativas orientadas a limitar el ejercicio de la libertad sindical en cualquiera de sus tres facciones (sindicación, negociación colectiva y huelga), estableciendo un número mínimo irrazonable de afiliados para la constitución de un sindicato, o poniendo trabas a la negociación en niveles superiores a los del sindicato de empresa, u otras trabas normativas. Así, Ermida plantea como interrogante si es posible que este tipo de políticas obedezcan a un móvil claramente antisindical, y no a una mera consecuencia natural de la inmadurez del sistema colectivo en nuestra región, en la cual, justamente, este tipo de restricciones legislativas se da de manera más común. Así, refiere que "a modo de ejemplo insuficiente y casi elemental, digamos que, en muchos regímenes latinoamericanos, tan afectos al registro sindical, este funciona en los hechos como un filtro discriminatorio. En forma mucho más general y ambiciosa habría que analizar si es o no cierto que en algunos países toda la legislación sindical estaría inspirada en un prejuicio o en un móvil antisindical y en qué medida, si fuera ello cierto, tal legislación constituiría ella misma, el principal acto antisindical" (Ermida 1987, 44).

Bronstein aporta un elemento adicional de sumo interesante a este respecto, presentando un supuesto de intervención conjunta de autoridades y empleadores, configurándose esta práctica cuando las autoridades dilatan el otorgamiento del registro sindical, otorgando con ello tiempo al empleador para despedir o trasladar a los trabajadores afiliados o que pretenden hacerlo. Así, señala que "una forma particularmente sofisticada de acoso antisindical consiste en la colusión entre las autoridades públicas y los empleadores: al tiempo que las primeras demoran el registro del sindicato, los segundos despiden o toman represalias contra los trabajadores que intentan sindicalizarse" (Bronstein 1995, 89)(11).

Al respecto, Ermida citando a Bartolomei, manifiesta que "una de las formas de discriminación antisindical se presenta en ocasión de la llegada al poder de gobiernos que favorecen los intereses patronales y cuando la autoridad pública hace causa común con los empleadores, lo que supone un acto antisindical cuyo sujeto activo es el Estado, en todo caso, en que el Estado es coautor o cómplice (Ermida 1987, 43).

3.1.3 Prácticas del empleador contra el sindicato como entidad colectiva

En segundo lugar, esta clase de prácticas buscan eliminar la eficacia representativa de los intereses de los trabajadores de los sindicatos como tales. Es decir, buscan restringir su posibilidad de actuar como interlocutores válidos, negándose por ejemplo a reconocer al sindicato como organización legitimada de negociación, cuestionando la validez de su inscripción, e incluso fomentando la constitución de sindicatos sostenidos económicamente por el empleador, restando así eficacia negocial a los sindicatos independientes.

Con relación a este tema, respecto del cual nos referiremos en más detalle en el capítulo siguiente del presente trabajo, Bronstein manifiesta lo que a la letra dice:

"En un segundo grupo, se encuentran las prácticas del empleador en contra del sindicato como entidad colectiva. Entre

(11) Así, Bronstein señala que "una forma particularmente sofisticada de acoso antisindical consiste en la colusión entre las autoridades públicas y los empleadores: al tiempo que las primeras demoran el registro del sindicato, los segundos despiden o toman represalias contra los trabajadores que intentan sindicalizarse" (Bronstein 1995). 
ellas, figura la negativa a reconocer al sindicato, a tratar y negociar con él. En América Latina, la práctica antisindical más caracterizada es probablemente el fenómeno de los 'sindicatos amarillos' o de asociaciones de trabajadores que se encuentran bajo control económico del empleador (Bronstein 1995, 89)."

Al respecto Blancas sostiene con acierto que "la libertad colectiva tiene como titular al sindicato, en cual, en virtud de esta, tiene derecho a la constitución y autoorganización, a ejercer libremente sus actividades, a federarse nacional e internacionalmente, y a la libre acción o actividad sindical, incluyendo la negociación colectiva y huelga" (Blancas 2006, 294). Es precisamente en atención a este reconocimiento de la fuerza equilibradora de la organización sindical al poder del empleador que "es frecuente que este oponga resistencia a la conformación y actuación de tales organizaciones, llegando inclusive a realizar actos discriminatorios que pueden ocurrir tanto en el momento genético de la relación laboral, o en el momento funcional, es decir, durante la relación laboral" (Blancas 2006, 294).

De este modo, lo que se persigue es precisamente impedir, a través de distintos mecanismos, que el sindicato, como organización colectiva se constituya y se organice a efectos de negociar con la contraparte empleadora. Así, cabe puntualizar que las alusiones a tipo de actos antisindicales no se circunscriben a los sindicatos como tales, es decir, como organizaciones registradas de trabajadores. Por el contrario, dentro de esta clasificación también se incluye a las prácticas antisindicales dirigidas contra la "actividad de organizarse", sea a través sí de un sindicato, o en un momento anterior a su nacimiento, a saber, en la etapa inicial o genética de organización. Ello implica cometer conductas desleales contra los trabajadores en proceso de organización colectiva.

Así, siguiendo a Ermida, la libertad sindical se refiere a un derecho de actividad, entendiendo que puede producirse actividad sindical aún cuando no se ha constituido un sindicato (por ejemplo, durante el intervalo en el cual se realizan actividades de proselitismo dirigido precisamente a lograr la afiliación. En este escenario, el referido autor uruguayo, citando a Gino Giugni, refiere que "la actividad sindical es un prius con respecto a la organización y una vez constituida esta, sigue siendo "el componente dinámico de la organización sindical” (Ermida 1987, 22).

Esto determina que también deben ser calificadas como conductas o prácticas antisindicales, las cometidas por los empleadores destinadas a evitar precisamente que los sindicatos se conformen, ya sea a través de medidas de desarticular al sindicato en su formación a través del otorgamiento de incentivos (ya sea económicos o de otra índole) a quienes no se afilien, o más concretamente fomentando la constitución de sindicatos patronales, controlados o patrocinados de alguna manera por el empleador, denominados por Ermida como sindicatos amarillos ${ }^{(12)}$, blancos ${ }^{(13)}$ o de paja.

Este tipo de sindicatos se definen como aquellas organizaciones controladas por un empleador u organización de empleadores, ya sea a través de control económico o financiero u otra forma de injerencia, orientadas a mermar la afiliación de trabajadores a sindicatos independientes, en una clara vulneración a su autonomía colectiva.

Este tipo de sindicato, si bien se denomina como tal para efectos de su estudio, no es propiamente tal, dado que el concepto jurídico de sindicato está referido a la organización de trabajadores, creada a fin de contrarrestar el poder del empleador al interior de la relación de trabajo, logrando, a través de su actuación libre de injerencias, la obtención de condiciones laborales y remunerativas más favorables para sus afiliados.

(12) Históricamente, se denominaban "amarillos", pues es de este color que los sindicalistas pintaban las casas de los trabajadores que no apoyaban la lucha reivindicativa no acatando las medidas de fuerza, en una señal de desprecio hacia aquellos, generando así presión social para abandonar la comunidad.

(13) En alusión a su inanidad. 
Apuntes en torno a las prácticas antisindicales: ¿Es realmente posible probarlas? Notes about anti union practices: it is really possible to test them?

\section{La prueba en materia de prácticas antisindicales y actos de injerencia}

A este respecto, es por todos conocido que, en materia de protección de los derechos fundamentales de los trabajadores (tanto los derechos específicos como los inespecíficos), la carga de la prueba plantea serios problemas. Ello debido a que aquel que considere que alguno de sus derechos se ha visto vulnerado por parte del empleador, deberá acreditar en sede judicial la violación alegada, con todas las dificultades que ello plantea.

Así, por ejemplo, cuando un trabajador ha sido víctima de un trato discriminatorio por motivo de su religión u opinión, aquel deberá demostrar en qué ha consistido la conducta antijurídica que ha vulnerado su derecho, lo cual resulta, en la práctica, sumamente complicado, pues se trata por lo general de conductas sutiles y que no dejan evidencia que permita construir una acusación, salvo que ello se haga a través de la reconstrucción de indicios.

Lo mismo sucede cuando estamos ante la violación del derecho fundamental a la libertad sindical, debiendo el trabajador sindicalizado o la organización sindical demostrar que determinada conducta se ha implementado con el ánimo perverso de violar sus derechos protegidos. Ello si bien plantea dificultades en todos los casos, tratándose de conductas antisindicales a título individual, es relativamente sencillo construir la red de indicios que permita demostrar la antijuridicidad de determinada conducta.

Ello sucede, por ejemplo, ante el despido, re-locación o traslado geográfico de un dirigente sindical en periodo de negociación colectiva. En este caso, dada la flagrancia del hecho, será el empleador quien deberá demostrar que el despido o traslado obedeció a alguna causa válida establecida en la ley en el primer caso, o razonable y en atención al ius variandi, sin ánimo de ocasionar perjuicio al dirigente, caso contrario, será relativamente sencillo concluir que el despido fue uno antisindical.

En cambio, tratándose de actos de injerencia del empleador en una organización de trabajadores (sindicatos amarillos, blancos o de paja), la actividad probatoria supone un problema quizás no mayor, pero definitivamente distinto. Así, frente a este supuesto, los trabajadores no sindicalizados o los afiliados a otro sindicato, serán quienes tengan que demostrar que determinado sindicato cuenta con apoyo o financiamiento del empleador. Es pues, trabajador contra trabajador discutiendo sobre la comisión de actos antisindicales (si bien la conducta transgresora deriva de un comportamiento del empleador como principal sujeto activo).

De este modo, el sindicato que pierda afiliados o que reciba menor número de afiliaciones derivadas de la existencia de un sindicato auspiciado por el empresario, deberá demostrar ya sea ante la autoridad administrativa correspondiente o ante un juez, que se está incurriendo en prácticas antisindicales proscritas en virtud del Convenio OIT 98.

Una primera aproximación para poder desarrollar esta actividad probatoria parte de la noción de discriminación. A partir de ella, se podrá articular la red de indicios que permita posteriormente, una inversión de la carga de la prueba. Así, cuando nos encontramos ante dos organizaciones sindicales, una de ellas, controlada por el empleador, se podrán detectar algunas conductas que manifiesten un tratamiento desigual sin que existan causas objetivas que lo sustenten, tanto en el plano de organización de las actividades, como en el marco de una negociación colectiva y la celebración de un convenio colectivo.

Respecto del primer plano, es decir, en la etapa de organización de la actividad sindical, entre las conductas más evidentes que podrían servir para detectar una práctica contraria a la libertad sindical, encontramos el otorgamiento, por un lado, y la denegación por otro, de un crédito de horas para la realización de actividad sindical a favor de los dirigentes. En este sentido, si bien en algunos ordenamientos jurídicos el crédito de horas (concepto más amplio que la licencia sindical) 
Lidia Vilchez Garcés

está reconocido como un derecho o garantía genéticos de la organización sindical(14), no lo es en nuestro país.

Así, por ejemplo, podría evidenciarse una conducta discriminadora y por motivos prohibidos ante el otorgamiento de mayores facilidades de tiempo a los dirigentes de un sindicato y la negativa de brindar las mismas facilidades al otro. Lo mismo se puede sostener en el caso del local para actividades (que, si bien sería demasiado flagrante el no otorgamiento a uno y sí a otro, efectivamente podría evidenciarse una discriminación, ante el equipamiento del local, su ubicación; a saber, la distancia respecto del centro de operaciones que agrupe al mayor número de trabajadores, o la asunción de los gastos que represente su mantenimiento, sin que ello haya sido expresamente pactado mediante convenio colectivo).

Por otro lado, en relación con la negociación colectiva, existen algunos factores que podrían resultar de utilidad para poner de manifiesto que un sindicato no cuenta en realidad con la representatividad requerida para arribar a acuerdos colectivos. Entre estos factores podemos encontrar: (i) el número de trabajadores afiliados al sindicato, (ii) la antigüedad y trayectoria del Sindicato en la Empresa, lo cual se vincula con su tradición (si supone de manera sostenida en el tiempo, una conducta pro empresario o si por el contrario, tiene un antecedente de lucha y logros reivindicativos); y, (iii) la capacidad de convocatoria y movilización, entre otros.

De este modo, coincidiendo a la doctrina española, podemos señalar lo siguiente:

"En términos generales, la representatividad trata de acreditar la aptitud y capacidad de una determinada organización profesional para desempeñar adecuadamente la representación de intereses dentro de su ámbito de actuación, ya sea porque cuenta con un gran número de afiliados o cotizantes, experiencia y antigüedad, capacidad de convocatoria y movilización, audiencia electoral, etc. Se trata, además de una cualidad que puede variar, y de hacho varía con el transcurso del tiempo" (Valverde 2002, 275).

Respecto del antecedente sindical (experiencia y antigüedad), si nos encontramos ante una organización sin antecedentes negociales, recién constituida, se añade una dificultad adicional, conforme es atendible, pues no existen elementos de comparación histórica que evidencien una tendencia antisindical.

Por otro lado, sin perjuicio de lo expuesto, debe tenerse en cuenta que la representatividad negocial no supone simplemente contar con un número mayoritario de afiliados, sino con coherencia entre el pliego de reclamos presentado al empleador y la realidad laboral al interior de la empresa o rama de actividad. Es decir, podremos sospechar de un pliego de reclamos condescendiente con el empresario o que no recoge en general las inquietudes del común de los trabajadores.

En este sentido por ejemplo, se podría intuir la existencia de injerencia del empleador tratándose de una empresa con serios problemas de seguridad y salud en el trabajo que presente un pliego que, conociendo tal situación, no recoja ninguna provisión al respecto, o de una empresa con salarios por debajo del nivel de mercado, que persiga como principal "reivindicación" el otorgamiento de un bono por no paralización o por asistencia y puntualidad, en lugar de requerir un incremento en las remuneraciones mensuales.

Otro indicio, ciertamente relativo, podría ser la rapidez con la cual las partes lleguen a un acuerdo. Por lo general, si bien se admiten excepciones, las negociaciones colectivas resultan ser procesos extensos que, en algunos casos, requieren incluso la adopción de medidas de fuerza para llegar a una solución. Dicho esto, si el Sindicato llega a un acuerdo con su contraparte dentro de parámetros temporales sumamente restringidos (por ejemplo, tan solo en dos o tres reuniones de trato directo), ello podría evidenciar una concertación previa, dirigida a

(14) En el ordenamiento español, el crédito de horas está recogido en el artículo 68 e) del Estatuto de Trabajadores. 
Apuntes en torno a las prácticas antisindicales: ¿Es realmente posible probarlas? Notes about anti union practices: it is really possible to test them?

no llegar al conflicto, arribando, por el contrario, a acuerdos más beneficiosos para sus miembros que para los afiliados a otros sindicatos.

En atención a lo expuesto, se entiende que la inversión de la carga de la prueba en casos de injerencia del empleador, sería una vía razonable de protección del derecho de libertad sindical de la organización de trabajadores, pues exigir a los sindicatos o trabajadores afectados un mayor despliegue probatorio, adicional a los indicios que deban aportar ante situaciones como las descritas, podría suponer indefectiblemente una vulneración irreparable al derecho a la libertad sindical, protegido tanto por la Constitución como por los convenios internacionales de trabajo.

\section{Conclusiones}

A lo largo del presente trabajo, se han analizado en esencia tres grandes temas; a saber, la libertad sindical, las prácticas antisindicales y finalmente de manera breve, lo que se conoce como sindicatos amarillos, blancos o de paja.

En este sentido, tras definir sucintamente qué se entiende por libertad sindical, se clasifican las prácticas o actos antisindicales en tres categorías: por un lado, las prácticas del empleador en contra de sindicalistas a título individual; por otro, las acciones u omisiones de las autoridades públicas en desmedro de los sindicatos, $y$; finalmente, las prácticas del empleador contra el sindicato como entidad colectiva. Es precisamente en este tercer grupo en el cual se enmarcan los sindicatos amarillos o de paja, que suponen, en contravención con lo dispuesto en el Convenio $\mathrm{N}^{\circ} 98$.

En este contexto, siendo que son precisamente los trabajadores afectados quienes deben acreditar que otros trabajadores se encuentran incursos en la comisión de prácticas antisindicales al aceptar injerencia del empleador, se requiere la acreditación cuando menos de algunos indicios razonables que generen cierta verosimilitud. Con tal aporte indiciario, correspondería invertir de la carga de la prueba.

Ello supone en consecuencia, que - aportados ciertos indicios en el marco de un procedimiento administrativo o proceso judicial - será el sindicato cuestionado, quien deberá demostrar su independencia funcional, económica o financiera. De lo contrario, se acreditará la injerencia, que resulta incuestionablemente, una lesión grave contra la libertad sindical, en tanto que erosiona el sistema de relaciones colectivas de trabajo al alterar la natural independencia que debe existir entre organizaciones de empleadores y de trabajadores.

\section{Referencias bibliográficas}

Blancas, Carlos. 2006. El despido en el Derecho Laboral Peruano, Lima: Ara Editores.

Bronstein, Arturo. 1995. Protección de la libertad Sindical. En El Derecho Sindical en América Latina, coords. Oscar Ermida Uriarte y Antonio Ojeda Avilés. Montevideo: Fundación de Cultura Universitaria.

Covington, R. y Decker K. 2002. Employment Law. U.S.A: West Group.

Ermida Uriarte, Oscar. 1987. La Protección contra los actos antisindicales. Montevideo: Fundación de Cultura Universitaria.

Ermida Uriarte, Oscar. 1988. Sindicatos en Libertad Sindical. Montevideo: Fundación de Cultura Universitaria.

Ermida Uriarte, Oscar y Antonio Ojeda Avilés. 1995. El Derecho Sindical en América Latina. Montevideo: Fundación de Cultura Universitaria.

Levaggi, Virgilio. 2006. Democracia y trabajo decente en América Latina. Lima: Oficina Internacional del Trabajo.

Mantero de San Vicente, Osvaldo. 1998. Derecho Sindical. Montevideo: Fundación de Cultura Universitaria.

Organización Internacional del Trabajo. 1995. Derecho Sindical de la OIT - Normas y Procedimientos. Ginebra: Oficina Internacional del Trabajo Ginebra. 


\section{Lidia Vilchez Garcés}

Pérez del Castillo, Santiago. 1995. Introducción al derecho de las relaciones colectivas de trabajo. Montevideo: Fundación de Cultura Universitaria.

Pronunciamientos del Comité de Libertad Sindical. http://webfusion.ilo.org/public/db/standards/ normes/libsynd/index.cfm?Lang=SP\&hdroff=1
Sindical del Consejo de Administración de la OIT. 2006. La Libertad Sindical: Recopilación de decisiones y principios del comité de Libertad. Ginebra: Oficina Internacional del Trabajo Ginebra.

Valverde, Antonio y otros. 2002. Derecho del Trabajo. Madrid: Editorial Tecnos. 